\title{
PENDIDIKAN KARAKTER MELALUI MATERI GEJALA PEMANASAN GLOBAL PADA ANAK USIA DINI
}

\author{
Wahyu Nurhidayat ${ }^{1}$, Nana ${ }^{1}$ \\ ${ }^{1}$ Pendidikan Fisika, Universitas Siliwangi, Indonesia \\ Email: wahyucahayapetunjuk@gmail.com
}

\begin{abstract}
The purpose of this petenilian is to implement character education in early childhood by using global warming symptom material. It can be seen at this time that the effects of global warming can be clearly felt. To minimize the impact of global warming, we need a good character in each individual. For this reason, character education is aimed at early childhood. Early childhood was chosen because it has a better tendency in planting and implementing good character in the future. The research method used is a literature study that is compiled comprehensively so that it gets relevant results. The results of this study explain that there is a relationship between character education through global warming symptoms that are applied to early childhood.
\end{abstract}

Keywords: Early Childhood, Symptoms of Global Warming, Character Education

ABSTRAK

Tujuan petenilian ini ialah untuk menerapkan pendidikan berkarakter pada anak usia dini dengan menggunakan materi gejala pemanasan global. Dapat dilihat pada saat ini bahwasannya efek dari pemanasan global sudah dapat dirasakan dengan jelas. Untuk meminimalisir dampak dari pemanasan global, maka diperlukan suatu karakter baik dalam diri setiap individu. Untuk itu, maka pendidikan karakter ditujukan pada anak usia dini. Anak usia dini dipilih karena memiliki kecenderungan lebih baik dalam penanaman dan implementasi karakter baik di masa yang akan datang. Metode penelitian yang digunakan ialah dengan studi pustaka yang disusun secara komperhensip sehingga mendapat hasil yang relevan. Hasil dari penelitian ini menjelaskan bahwa terdapat hubungan antara pendidikan karakter melalui gejala pemanasan global yang diterapkan pada anak usia dini.

Kata kunci: Anak Usia Dini, Gejala Pemanasan Global, Pendidikan Karakter

\section{PENDAHULUAN}

Planet bumi semakin lama semakin tua. Berbagai fenomena pun kian terjadi seperti bencana. Berdasarkan Undang-Undang Nomor 24 Tahun 2007 Tentang Penanggulangan Bencana, bencana Bencana adalah peristiwa atau rangkaian peristiwa yang mengancam dan mengganggu kehidupan dan penghidupan masyarakat yang disebabkan, baik oleh faktor alam dan/atau faktor nonalam maupun faktor manusia sehingga mengakibatkan timbulnya korban jiwa manusia, kerusakan lingkungan, kerugian harta benda, dan dampak psikologis. Bencana alam timbul akibat dari alam itu sendiri, seperti gempa bumi, tsunami, gunung meletus, dan sebagainya. Bencana non-alam dapat dicontohkan misalnya, gagal panen akibat serangan hama dan wabah penyakit. Kemudian untuk bencana akibat dari perbuatan manusia salah satunya ialah banjir dan pembakaran hutan. Akan tetapi, pada kenyataannya beberapa bencana alam maupun non-alam pun sebenarnya terjadi akibat dari kurang sadarnya manusia terhadap alam sekitar. Salah satu contoh dari bencana tersebut adalah pemanasan global yang menyebabkan naiknya permukaan air laut dan suhu ekstrim di berbagai wilayah.

Berdasarkan temuan dari Intergovernmental Panel on Climate Change (IPCC) menunjukkan bahwa (1) suhu permukaan diproyeksikan naik sebesar $1,4^{\circ} \mathrm{C}$ hingga $5,8^{\circ} \mathrm{C}$ sebagai rerata global dari tahun 1990-2100, (2) pemanasan (perluasan panas) lautan beserta melelehnya 
glister dan es di atas tanah akan menyebabkan kenaikan permukaan air laut di seluruh dunia, rerata permukaan air laut diproyeksikan naik sebesar 0,09 hingga 0,88 meter antara tahun 1990 dan 2100 ini akan berlangsung terus menerus menerus meskipun konsentrasi gas rumah kaca di atmosfer distabilkan, (3) kejadian cuaca ekstrem seperti gelombang panas, kemarau dan banjir, diprediksikan akan meningkat, begitu pula suhu minimum yang lebih tinggi dan periode dingin yang lebih pendek, dan (4) gletser dan puncak es diproyeksikan terus menyusut secara luas selama abad ke21 dengan gletser tropis dan sub-tropis paling banyak menyusut dan pada beberapa kasus telah lenyap (Mukono, 2018: 69). Pada kasus ini, penanaman karakter yang baik harus ditanamkan untuk mewujudkan kearifan manusia dalam menjaga lingkungan. Kebijaksanaan dari manusia bisa saja dapat meminimalisir dampak buruk dari pemanasan global

Karakter adalah suatu sifat yang diimplementasikan dengan sikap baik yang dimiliki oleh setiap manusia. Dalam pendidikan karakter, seseorang diharapkan dapat memiliki dan menerapkan karakter yang baik dalam kehidupannya. Dari karakter baik tersebut dapat menjadi titik awal seorang manusia bisa menjaga dan merawat alam atau lingkungan. Penanaman pendidikan karakter dapat diterapkan pada anak usia dini. Menurut Permono (2013) usia dini lahir sampai 6 tahun merupakan usia yang sangat menentukan dalam pembentukan karakter dan kepribadian seorang anak. Pada masa tersebut karakter anak mudah dibentuk dan dari sinilah fase yang sangat menentukan karakter seorang anak untuk ke depannya.

Penanaman karakter sangat penting bagi anak usia dini. Cakupan dari keluasan dan rincian materi gejala pemanasan global disesuaikan dengan kebutuhan. Menurut Nana (2014), keluasan materi menggambarkan seberapa banyak materimateri yang dimasukkan, sedangkan kedalaman materi menyangkut rincian konsep-konsep yang terkadang di dalamnya, yang harus dipelajari oleh siswa. Siswa dalam hal ini ialah anak usia dini yang dibimbing oleh orang tua dari anak tersebut.

\section{METODE PENELITIAN}

Penelitian ini menggunakan pendekatan kualitatif berupa data teoritis dengan metode penelitian studi pustaka. Metode penelitian studi pustaka artinya peneliti mengambil data melalui kegiatan membaca literatur yang relevan dengan kajian penelitian yang dilakukan. Data dikumpulkan untuk dianalisis kemudian disajikan dalam hasil dan pembahasan agar dapat dibuat kesimpulan.

\section{HASIL DAN PEMBAHASAN}

\section{Gejala Pemanasan Global}

Pemanasan global adalah fenomena peningkatan temperatur global dari tahun ke tahun karena terjadinya efek rumah kaca (greenhouse effect) yang disebabkan oleh meningkatnya emisi gas-gas seperti karbondioksida (CO2), metana (CH4), dinitrooksida (N2O) dan CFC sehingga energi matahari terperangkap dalam atmosfer bumi (Rosana, dkk, 2019).

Pemanasan global atau bisa disebut global warming merupakan salah satu permasalahan lingkungan secara global. Pemanasan global merupakan suatu kondisi di mana meningkatnya suhu rerata bumi. Meningkatnya suhu rerata tersebut diakibatkan dari radiasi sinar matahari yang tidak dapat dipantulkan 
kembali menuju luar atmosfer, sehingga panas dari radiasi tersebut akan terperangkap dan mengakibatkan suhu meningkat. Penyebab utama pemanasan global ialah efek rumah kaca. Efek rumah kaca ini terjadi salah satunya sebab penggunaan bahan bakar dari fosil, dan kerusakan hutan.

Menurut Hidayati (Cahyono, 2007), gas CO: memberi kontribusi terbesar dalam pemanasan global yaitu $50 \%$. Selanjutnya kontribusi hingga terkecil diberikan oleh gas-gas CFCs, $\mathrm{CH}_{4}$ (metana), $\mathrm{O}_{3}$, dan $\mathrm{NO}_{\mathrm{x}}$ masingmasinglebih kurang $20 \%, 15 \%, 8 \%$, dan $7 \%$. uap air juga merupakan gas rumah kaca, tetapi karena air dianggap tetap (alam), maka air tidak dianggap sebagai penyebab perubahan iklim oleh pemanasan global.

Dampak dari pemanasan global dapat dikatakan banyak mendatangkan kerugian. Beberapa dampak tersebut adalah iklim yang mulai tidak stabil, es di kutub yang mulai mencair, persediaan pangan yang akan terganggu, keberlangsungan hewan dan tumbuhan yang akan terganggu, serta kesehatan manusia yang rentan terkena penyakit. Pemanasan global dapat menimbulkan ketidak-stabilan iklim. Ketidak-stabilan ini dapat menimbulkan cuaca ekstrem bahkan dapat menimbulkan bencana alam seperti angin tornado dan sebagainya. Kemudian, ketika es di kutub mulai mencair, maka secara otomatis permukaan air laut pun akan semakin naik. Kenaikan air laut tersebut dapat menyebabkan beberapa pulau di beberapa negara akan tenggelam. Lalu, pemanasan global pun akan menimbulkan banyak kerugian dalam bidang ekonomi seperti menurunnya ketersediaan pangan akibat dari berbagai kondisi yang dapat merusak tanaman produksi atau gagal panen. Selain itu, keberlangsunan makhluk hidup dan kesehatan manusia pun akan terpengaruhi oleh dampak pemanasan global, sebab beberapa kondisi akibat pemanasan global akan saling mempengaruhi pada aspek yang satu dengan aspek yang lainnya.

\section{Pendidikan Karakter Anak Usia Dini}

Karaktek atau watak merupakan sifat-sifat kejiwaan yang melahirkan suatu tindakan dari seorang manusia. Karakter seserang perlu dibentuk dan diarahkan agar memiliki suatu perilaku yang baik (good attitude). Karakterkarakter tersebut dapat diajarkan melalui suatu proses yang disebut dengan pendidikan.

Dalam pengertian menurut Undang-Undang Nomor 20 Tahun 2003 Tentang Sistem Pendidikan Nasional pada Pasal 1 Ayat 1, pendidikan adalah usaha sadar dan terencana untuk mewujudkan suasana belajar dan proses pembelajaran agar peserta didik secara aktif mengembangkan potensi dirinya untuk memiliki kekuatan spiritual keagamaan, pengendalian diri, kepribadian, kecerdasan, akhlak mulia, serta keterampilan yang diperlukan dirinya, masyarakat, bangsa dan negara.

Menurut Samani dan Hariyanto (dalam Hasanah, 2016), karakter adalah sesuatu yang penting dan vital bagi tercapainya tujuan hidup. Karakter adalah mustika hidup yang membedakan manusia dengan binatang. Karakter merupakan dorongan pilihan untuk menentukan yang ter-baik dalam hidup. Karakter juga dapat diartikan sebagai cara 
berpikir dan berperilaku yang khas tiap individu untuk hidup dan bekerja sama, baik dalam lingkup keluarga, masyarakat, bangsa, dan Negara. Individu yang berkarakter baik adalah individu yang dapat membuat keputusan dan siap mempertanggungjawabkan setiap akibat dari keputusannya.

Pada umumnya, pendidikan karakter dapat ditanamkan sejak dini di lingkungan keluarga. Pasalnya pada lingkungan keluarga seorang anak pertama kali mendapatkan suatu pendidikan oleh orang tuanya. Oleh sebab itu, orang tua atau lingkungan keluarga merupakan faktor terpenting dalam penanaman karakter pada seorang individu dalam fase anak usia dini.

Dalam fase usia dini anak dapat dibekali karakter-karakter positif untuk bekal ketika ia masuk bangku sekolah. Selain itu, pembekalan karakter ini diharapkan suapaya anak mendapatkan hasil belajar yang maksimal. Menurut Nana Sudjana (dalam Nana, 2019), Hasil belajar adalah ke-mampuankemampuan yang dimiliki siswa setelah ia menerima pengalaman belajarnya. Klasifikasi hasil belajar dari Benyamin Bloom yang secara garis besar membaginya menjadi tiga ranah, yaitu: (1) ranah kognitif, (2) ranah afektif, (3) ranah psikomotor.

\section{Inovasi Pembelajaran Berbasis Karakter}

Seiring dengan berkembangnya zaman, maka segala hal dalam dunia ini pun akan ikut berkembang, termasuk dalam dunia pendidikan. Inovasi menyangkut pada sebuah ide, gagasan, praktik yang diterima dalam masyarakat sebagai suatu yang baru dan mutakhir. Berkaitan dengan inovasi, pendidikan juga memerlukan pembaharuan untuk menyesuaikan perkembangan zaman sesuai kebutuhan yang disebut dengan inovasi pembelajaran (Nana, 2018). Menurut Walder (dalam Nana, 2018), secara harfiah, inovasi berarti penyesuaian, perbaikan, pengembangan, proyek, percobaan, reformasi atau pembaharuan. Inovasi terletak pada rencana, metode, proses, teknologi, dan bagaimana cara implementasinya melalui transformasi.

\section{Penerapan Pendidikan Karakter melalui Materi Gejala Pemanasan Global pada Anak Usia Dini}

Berbagai kerugian besar dari pemanasan global tentunya menjadi suatu perhatian yang serius. Selain usaha-usaha dalam skala besar, seseorang pun dapat meminimalisir maupun mencegah pemanasan global tersebut dalam skala kecil. Penanaman karakter pada anak usia dini agar selalu menjaga dan merawat lingkungan dapat diterapkan.

Karakter baik dapat diterapkan dalam kehidupan sehari-hari anak usia dini secara sederhana. Penerapan karakter tersebut, misalnya: mengajarkan kepada anak usia dini untuk menghemat energi, mematikan AC ketika tidak digunakan, berjalan kaki maupun menaiki speda untuk bepergian dengan jarak yang dekat, menggunakan transportasi umum daripada kendaraan pribadi, meanam pohon untuk menghasilkan lebih banyak oksigen, sumber air bersih, dan sebagainya, dan membuang sampah pada tempatnya. 
Alur penerapan pendidikan karakter pada anak usia dini.

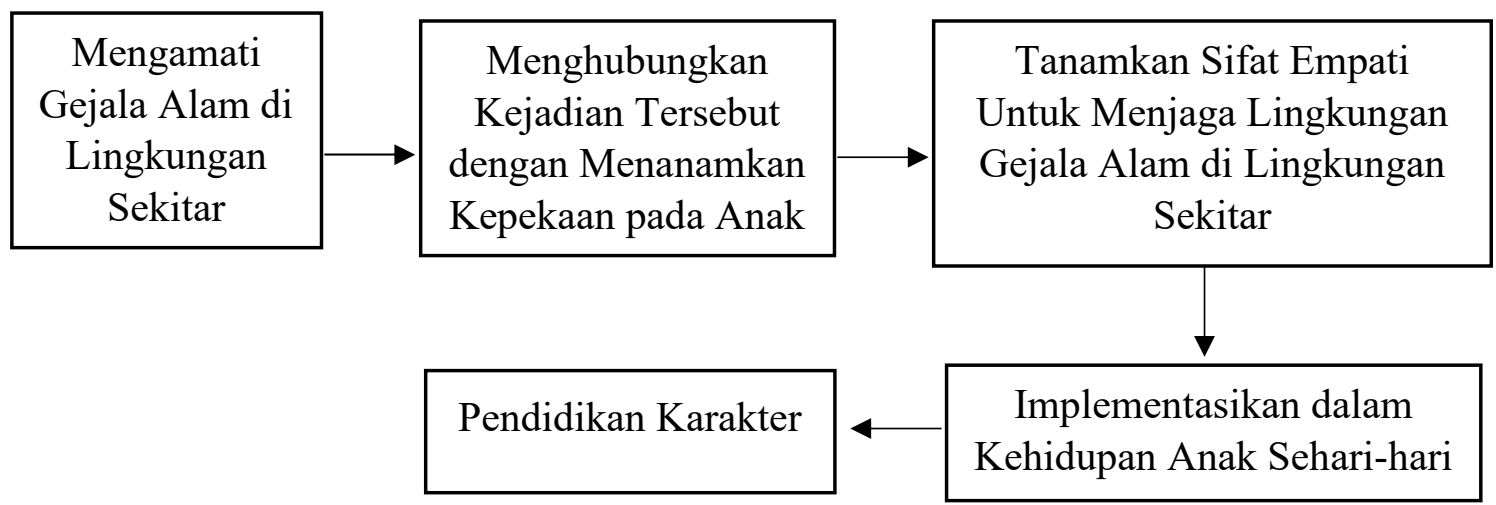

\section{PENUTUP}

Berdasarkan pada pemaparan yang telah disampaikan, maka dapat ditarik kesimpulan bahwasannya penanaman pendidikan karakter sangatlah penting diberikan. Penanaman karakter tersebut dapat diberikan melalui pemahaman materi dasar dari gejala pemanasan global. Sebagaimana yang banyak orang mengetahui, bahwa gejala pemanasan global dapat dirasakan dalam kehidupan manusia pada saat ini. Oleh sebab itu, maka dari gejala tersebut dapat dihubungkan dengan penanaman karakter baik oleh orang tua pada anak usia dini.

\section{UCAPAN TERIMA KASIH}

Peneliti mengucapkan banyak terima kasih kepada seluruh pihak yang berperan serta dalam penelitian ini khususnya kepada Dr. Nana, M.Pd. yang telah ikut serta membimbing dan memberikan arahan agar peneliti menjadi lebih baik lagi.

\section{REFERENSI}

Cahyono, W. E., 2007. Pengaruh Pemanasan

Global Terhadap Lingkungan
Bumi. Bidang Pengkajian Ozon dan Polusi Udara LAPAN. 8 (2): 28-31.

Hasanah, Uswatun. 2017. Pola Asuh Orangtua dalam Membentuk Karakter Anak. Dasar: Jurnal Ilmiah Pendidikan Dasar. 2 (2): $72-82$

Mukono, H. J. 2018. Analisis Kesehatan Lingkungan Akibat Pemanasan Global. Surabaya: Airlangga University Press.

Nana, N. (2018). Penerapan Model Creative Problem Solving Berbasis Blog Sebagai Inovasi Pembelajaran di Sekolah Menengah Atas dalam Pembelajaran Fisika. Prosiding SNFA (Seminar Nasional Fisika dan Aplikasinya), 190-195.

Nana, N. (2019). Upaya Peningkatan Kemampuan Kognitif dan Komunikasi Ilmiah Siswa Kelas X MIA 1 SMA Negeri 1 Ciamis Menggunakan Model Pembelajaran Inquiry. Diffraction Journal for Physics Education and Applied Physics. (pp 1-10).

Nana, Sajidan, Akhyar, M., \& Rochsantiningsih, D. (2014). Pengembangan Pembelajaran Fisika SMA Melalui Elaboration 
Write and Evaluation (EWE)

dalam Kurikulum 2013. Seminar

Nasional Pendidikan Sains.

[Online]. Tersedia:

https://jurnal.fkip.uns.ac.id/index.

php/ snps/article/view/4944 [12

Februari 2020].

Permono, Hendarti. (2013). Peran Orangtua

dalam Optimalisasi Tumbuh

Kembang Anak untuk Membangun

Karakter Anak Usia Dini. Proiding

Seminar Nasional Fisika dan

Aplikasinya. Surakarta, Indonesia.

34-47.

Republik Indonesia. 2003. Undang-Undang

Nomor 20 Tahun 2003 Tentang

Sistem Pendidikan Nasional.

Lembaran Negara RI Tahun 2003.

Sekretariat Negara. Jakarta.

Republik Indonesia. 2007. Undang-Undang

Nomor 24 Tahun 2007 Tentang

Penanggulangan Bencana.

Lembaran Negara RI Tahun 2007.

Sekretariat Negara. Jakarta.

Rosana, E., Hakim, N., Yunita. 2019.

Penyuluhan Dampak Perubahan

Iklim dan Adaptasinya terhadap

Usahatani Petani Karet dan Nanas

di Desa Burai. Jurnal Pengabdian

Sriwijaya. 7 (3): 844-850. 